ICACCG2020 30-31 July, 2020, Ansal University, Gurgaon, India

International Journal of Technical Research \& Science (Special Issue) ISSN No.:2454-2024 (online)

\title{
AN ASSESSMENT OF APPLICATION OF NANOMATERIALS FOR TREATING EMERGING CONTAMINANTS IN WATER
}

\author{
Priyanka Gupta ${ }^{1}$, Gaurav Tamrakar ${ }^{2}$ \\ E-Mail Id: ${ }^{1}$ priyanka.84may@gmail.com, ${ }^{2}$ gaurav.tamrakar@kalingauniversity.ac.in \\ ${ }^{1}$ Department of Applied Chemistry, Shri Shankaracharya Technical Campus, Junwani, Bhilai, Chhattisgarh, \\ India \\ ${ }^{2}$ Department of Mechanical Engineering, Kalinga University, Naya Raipur, Chhattisgarh, India
}

\begin{abstract}
The hastily growing population, depleting water resources, and weather change resulting in prolonged droughts and floods have provided drinking water with a coveted status among other natural resources. Nanotechnology-based totally multifunctional and exceptionally efficient approaches are supplying affordable solutions to water/wastewater treatments that do not depend on massive infrastructures or centralized systems. The aim of the present observation is to review the feasible packages of the nanoparticles/fibers for the removal of pollution from water/wastewater. The paper will briefly evaluate the supply and practice of various nanomaterials (particles or fibers) for removal of viruses, inorganic solutes, heavy metals, steel ions, complex natural compounds, herbal natural count, nitrate, and other pollutants present in floor water, ground water, and/or industrial water. Eventually, proposals are made based on the current practices of nanotechnology packages in water enterprise for an independent water purification unit for casting off all sorts of contaminants from wastewater.
\end{abstract}

Keywords: Nanomaterials, Water treatment, Adsorption.

\section{INTRODUCTION}

Clean water is one of the maximum crucial factors for all dwelling organisms to preserve life. However, due to the rapid pace of industrialization and huge increase in the population, the contamination of water sources has come about globally. [1-2]. Besides other factors, the demand for water has expanded extensively in agricultural, industrial and domestic sectors drinking 70, 22 and 8 percent of the water had to be clean water, respectively and this has resulted in the technology of large quantities of wastewater [3-4] containing some of "pollutants. Some of the essential types of aquatic pollution are heavy metal ions and dyes, and once those enter into the water, water is not safe for ingesting purpose and every now and then it's miles very hard to absolutely treat the contaminated water [56]. Aquatic pollution is regularly very risky for living beings, and also have an effect on the surroundings. Therefore, the removal of those pollutants from infected water is an urgent need so that it will prevent the bad outcomes on the human health and to the environment.

From past few years, various strategies had been advanced for treating the waste water [7-8]. Amongst them, maximum vital methods are solvent extraction, micro and ultrafiltration, sedimentation and gravity separation, flotation, precipitation, coagulation, oxidation, evaporation, distillation, reverse osmosis, adsorption, ion alternate, electrodialysis, electrolysis, and many others. From above mentioned strategies, adsorption is one of the immense techniques for treating the waste water due to low cost and the provision of a wide range of adsorbents [9-10].

In the last many years, nanotechnology has emerged considerably with its packages in nearly all branches of technological know-how and generation. As a reminder of truth, numerous nanomaterials have been organized and used for the removal of aquatic pollutants [11]. One of the targets of the prevailing evaluation is to assemble updated and vital findings of different kinds of nanomaterials, used in water which remedy either as adsorbents, photocatalyst and/or antibacterial sellers, for the removal of important aquatic pollution. A summary of relevant published facts with a number of the latest essential findings, and a source of literature is presented and the consequences have been discussed.

\section{NANOMATERIALS AS ADSORBENTS FOR WATER TREATMENT}

Nano adsorbents are nanoscale particles from organic or inorganic substances that have a high affinity to adsorb materials. Because of their high porosity, small size, and active surface, nano adsorbents not are able to sequestering contaminants with varying molecular length, hydrophobicity, and speciation conduct, but also allow production technique to consume unwanted materials correctly without liberating its toxic payload [12]. Nano adsorbents are not work quickly, however also have sizeable pollutant-binding capacities. They also can be chemically regenerated after being exhausted [13]. For those motives, scholarly hobbies of nanotechnology were growing hastily global. At the nanoscale, materials show specific properties because of their small size, they own a large surface area and 'surface region to volume' ratio [14]. These traits improve the adsorption capacity of the nanoparticles. Further to the large surface area, those particles display particular traits, along with catalytic ability and excessive reactivity, which lead them to as higher adsorbing materials than traditional materials. Because of their excessive surface area, 
ICACCG2020 30-31 July, 2020, Ansal University, Gurgaon, India

International Journal of Technical Research \& Science (Special Issue) ISSN No.:2454-2024 (online)

nanoparticles have a greater quantity of lively sites for interaction with one-of-a-kind chemical species [15-16]. To get higher consequences for the removal of pollutants from wastewater, nanoparticles have become new alternatives for the remedy of wastewater [17-18].
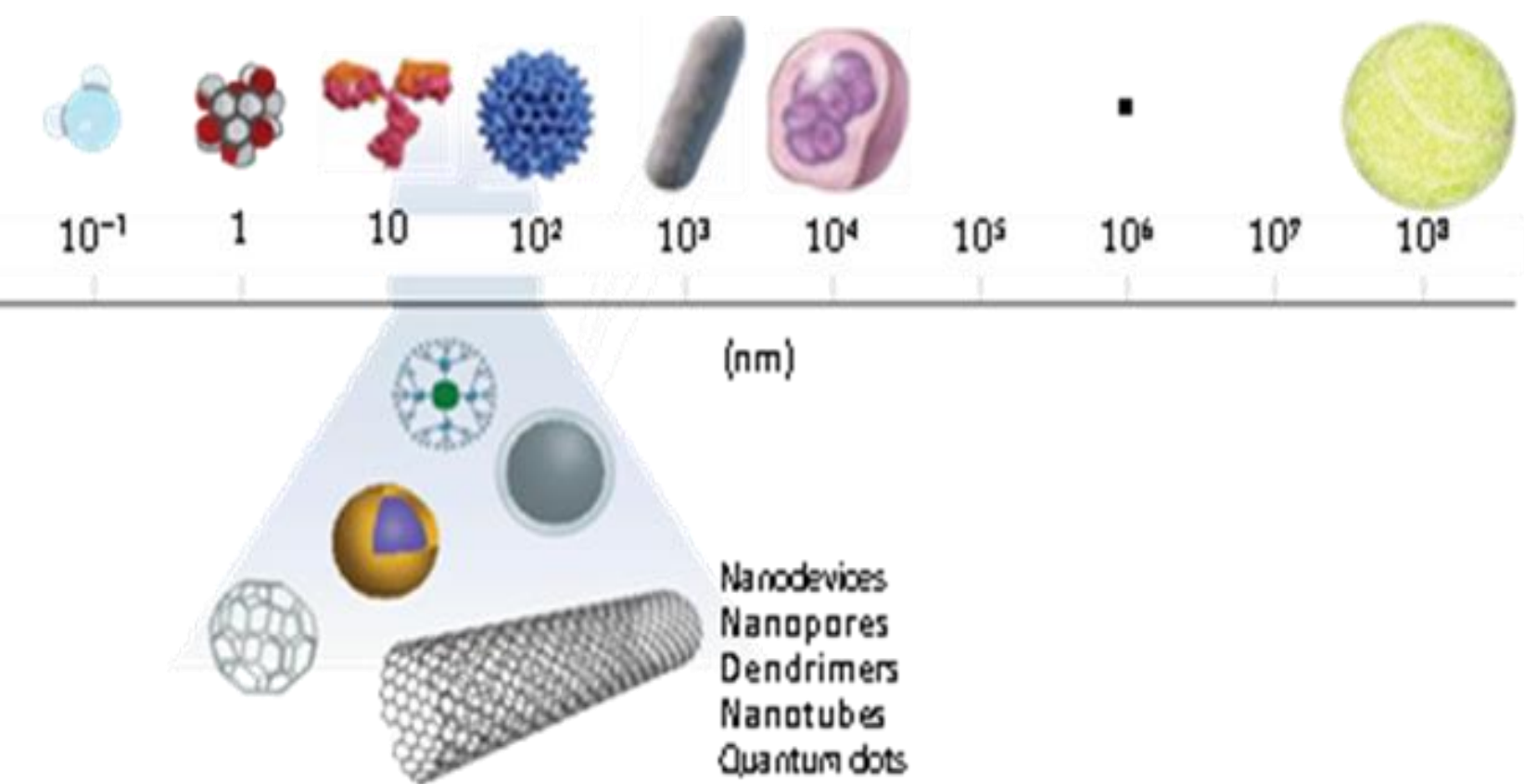

Fig. 2.1 A Size Comparison of Nanoparticle with Other Larger-Sized Materials

\subsection{Carbon Based Materials}

For any adsorption system, an adsorbent having big surface location, pore extent, and proper functionalities is the key to fulfilment. Presently, many exceptional porous substances were advanced, which includes activated carbon, pillared clays, zeolites, mesoporous oxides, polymers and metallic-organic frameworks, showing varying volume of effectiveness in eliminating the toxic pollutants from air, water and soil [19-20]. Among them, carbon-based totally adsorbents consisting of activated carbon, carbon nanotubes, fullerenes and graphene, typically show high adsorption ability and thermal stability [21-22]. Of the various nanomaterials primarily based adsorbents, carbon based totally materials have been probed as superior adsorbents for the elimination of inorganic and organic pollutants. Because the discovery of carbon nanotubes (CNTs) and fullerene, these substances had been extensively used as effective adsorbents but its large-scale utility is restrained on monetary grounds and consequently, designing the adsorbents at a lower cost is a splendid task. Multiwalled carbon nanotube shows tremendous elimination efficiency of inorganic metal ions with the help of magnetic nanomaterials [23].

\subsection{Carbon Nanotubes (CNTs)}

Carbon nanotubes are one of the allotropes of carbon. Basically, CNTs are composed of cylindrical shape rolled up in a tube-like shape. CNTs are of two kinds, single walled carbon nanotubes (SWCNTs) and multiwalled carbon nanotubes (MWCNTs), in which single walled carbon nanotubes are composed of single graphene sheet with a roll up and multiwalled carbon nanotubes are of more than one graphene roll up sheet. CNTs, having highly active site surface to quantity ratio and controlled pore length distribution, have a wonderful sorption capability and high sorption efficiency compared to standard granular and powder activated carbon, that have intrinsic barriers like surface active sites and the activation strength of sorption.

Table-2.1 Removal of Organic Pollutants Using Various Types of Carbon Nanotubes

\begin{tabular}{|l|l|l|l|}
\hline S. No. & Type of CNTs & Organic pollutants & \multicolumn{1}{|c|}{$\begin{array}{l}\text { Adsorption } \\
\text { capacity (mg/g) }\end{array}$} \\
\hline 1. & Alkali-activated MWCNTs & Methylene blue & 399 \\
\hline 2. & Untreated MWCNTs & Methylene blue & 59.7 \\
\hline 3. & Untreated SWCNTs & $\begin{array}{l}\text { Reactive red 120 } \\
\text { (RR -120) }\end{array}$ & 426.49 \\
\hline 4. & Oxidized SWCNTS & $\begin{array}{l}\text { Basic red 46 (BR } \\
\text { 46) }\end{array}$ & 49.45 \\
\hline 5. & Untreated MWCNTs & Tetracycline (TC) & 269.54 \\
\hline 6. & MWCNTs & Olaquindox & $99.7 \%$ \\
\hline 7. & SWCNTs & $\begin{array}{l}\text { 4-Chloro-2- } \\
\text { nitrophenol }\end{array}$ & 1.44 \\
\hline
\end{tabular}

DOI Number: https://doi.org/10.30780/specialissue-ICACCG2020/030 
ICACCG2020 30-31 July, 2020, Ansal University, Gurgaon, India

International Journal of Technical Research \& Science (Special Issue) ISSN No.:2454-2024 (online)

\begin{tabular}{|c|l|l|c|}
\hline 8. & MWCNTs & $\begin{array}{l}\text { 4-Chloro-2- } \\
\text { nitrophenol }\end{array}$ & 4.42 \\
\hline 9. & Untreated SWCNTs & $\begin{array}{l}\text { Dissolved organic } \\
\text { matter (DOM) }\end{array}$ & $26.1-20.8$ \\
\hline 10. & KOH activated MWCNTs & $\begin{array}{l}\text { Toluene, } \\
\text { ethylbenzene, } \mathrm{m}-\end{array}$ & $\begin{array}{l}87.12,322.05, \\
\text { xylene }\end{array}$ \\
\hline 11. & MWCNTs & Methyl orange & 52.86 \\
\hline 12. & Chitosan/Fe $\mathrm{O}_{3} /$ MWCNTs & Methyl orange & 66.90 \\
\hline
\end{tabular}

1)

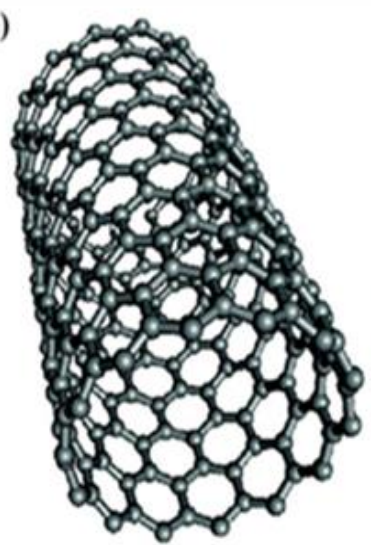

(b)

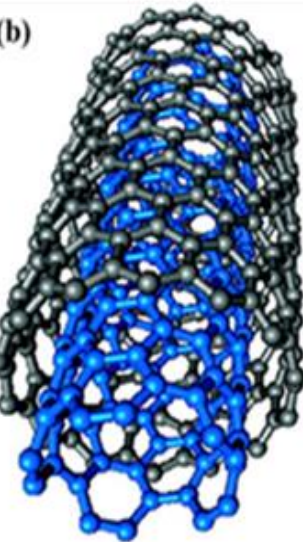

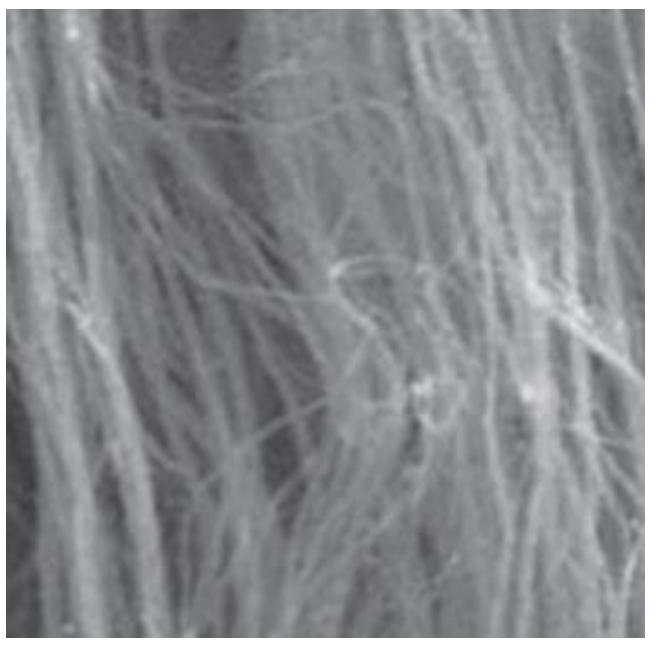

Fig. 2.2 Structure Representations (a) SWCNTs (b)MWCNTs (c) SEM Image of Aligned CNTs 2.3Graphene Based Materials

Table-2.2 Adsorption of Organic Pollutants Using Graphene Based Materials

\begin{tabular}{|c|c|c|c|}
\hline $\begin{array}{l}\text { S. } \\
\text { No. }\end{array}$ & Types of Graphene based materials & Organic pollutants & $\begin{array}{l}\text { Adsorption } \\
\text { capacity (mg/g) }\end{array}$ \\
\hline 1. & Polyether sulfone/GO & MB & 62.50 \\
\hline 2. & $\mathrm{Fe}_{3} \mathrm{O}_{4} / \mathrm{GO}$ hybrids & $\mathrm{MB}, \mathrm{NR}$ & $167.2,171.3$ \\
\hline 3. & Reduced GO- $-\mathrm{MFe}_{2} \mathrm{O}_{4}$ hybrids & $\mathrm{RhB}, \mathrm{MB}$ & $\begin{array}{l}92 \% \text { and } \\
100 \%\end{array}$ \\
\hline 4. & GO sponge & $\mathrm{MB}, \mathrm{MV}$ & 397,467 \\
\hline 5. & Reduced GO/ZnO nanohybrids & $\mathrm{RhB}, \mathrm{MB}$ & - \\
\hline 6. & Reduced GO/CdS hybrids & MB & $94 \%$ \\
\hline 7. & Reduced $\mathrm{GO}-\mathrm{TiO}_{2}$ & MO & - \\
\hline 8. & $\mathrm{Fe}_{3} \mathrm{O}_{4}-\mathrm{GNs}$ & $\mathrm{MB}, \mathrm{CR}$ & $45.3,33.7$ \\
\hline 9. & GO & MB & 351 \\
\hline 10. & GNs & MB & $154-204$ \\
\hline 11. & GO & Tetracycline & 313.48 \\
\hline 12. & $\mathrm{GO}$ & Oxytetracycline & 212.31 \\
\hline
\end{tabular}

\subsection{Metal Oxide-Based Nanomaterials}

Nano metallic oxides a few of the available adsorbents, nanosized metal oxides (NMOs), consisting of nanosized ferric oxides, manganese oxides, aluminum oxides, titanium oxides, magnesium oxides and cerium oxides, are

DOI Number: https://doi.org/10.30780/specialissue-ICACCG2020/030

pg. 38 
ICACCG2020 30-31 July, 2020, Ansal University, Gurgaon, India

International Journal of Technical Research \& Science (Special Issue) ISSN No.:2454-2024 (online)

categorized as the promising ones for elimination of pollutants from aqueous systems [27-28]. That is in part because of their big surface area and excessive activities caused by the scale quantization effect [29-30]. Recent studies suggested that many NMOs show off favorable sorption to heavy metals in terms of excessive capability and selectivity, which would result in high removal of poisonous metals [31]. But, as the dimensions of the steel oxides reduces from micrometer to nanometer tiers, the expanded surface strength inevitably ends in their low quality. Consequently, NMOs are susceptible to agglomeration because of van der Waals forces or different interactions [32], and the excessive potential and selectivity of NMOs could be significantly decreased or even lost. moreover, NMOs are unusable in constant bedsor another drift through structures because of the excessive strain drops (or the hard separation from aqueous structures) and less mechanical strength. To enhance the applicability of NMOs in actual wastewater remedy, those have been impregnated into porous supports of big size to gain composite adsorbents [33].
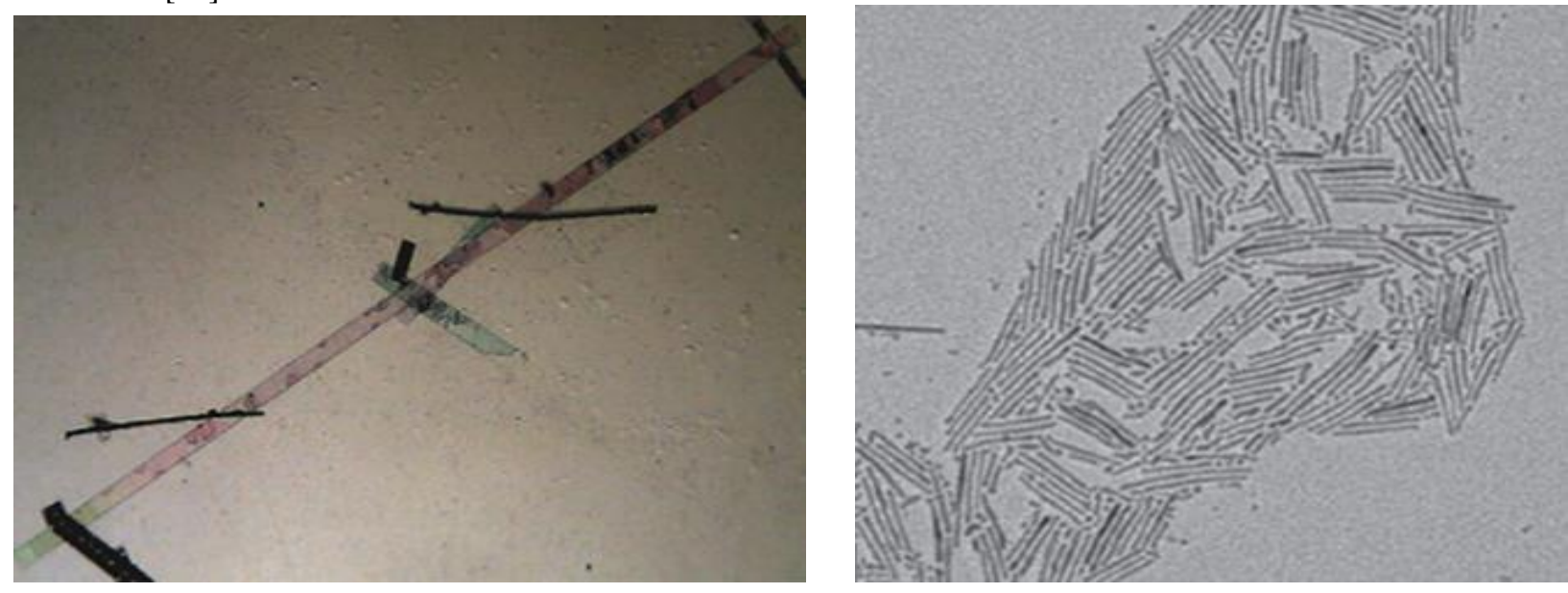

Fig. 2.3 (a) Optical Microscope Image of Sn-doped ZnOnanobelts $\quad$ (b) TEM Image of TiO2 Nanocrystals

Table-2.3 Removal of Organic Pollutants Using Nano Metal Oxides

\begin{tabular}{|c|c|c|c|}
\hline S. No. & $\begin{array}{l}\text { Types of Nano metal oxides } \\
\text { materials }\end{array}$ & Organic pollutants & $\begin{array}{c}\text { Adsorption } \\
\text { capacity (mg/g) }\end{array}$ \\
\hline 1. & $\mathrm{SiO}_{2} / \mathrm{Fe}_{3} \mathrm{O}_{4}$ & MO & 53.19 \\
\hline 2. & c- $\mathrm{Fe}_{2} \mathrm{O}_{3} / \mathrm{SiO}_{2} /$ chitosan composite & MO & 34.29 \\
\hline 3. & c- $-\mathrm{Fe}_{2} \mathrm{O}_{3}$ crosslinked chitosan composite & MO & 29.46 \\
\hline 4. & Magnetic nano powder & Phenol & 13.5 \\
\hline 5. & c- $\mathrm{Fe}_{2} \mathrm{O}_{3} / 2 \mathrm{C}$ nanocomposite & Phenol & 42.34 \\
\hline 6. & c- $\mathrm{Fe}_{2} \mathrm{O}_{3} / 2 \mathrm{C}$ nanocomposite & MO & 72.68 \\
\hline 7. & $\mathrm{c}-\mathrm{Fe}_{2} \mathrm{O}_{3}$ & Acridine orange & 59 \\
\hline 8. & Polyacrylic acid- $\mathrm{Fe}_{3} \mathrm{O}_{4}$ & MB, Crystal violet & 199,116 \\
\hline 9. & $\mathrm{Fe}_{3} \mathrm{O}_{4}-\mathrm{CTAB}$ & Acid red 27 & 1.05 \\
\hline 10. & CTAB- $-\mathrm{Fe}_{3} \mathrm{O}_{4} / \mathrm{SiO}_{2}$ & Phenolic compounds & - \\
\hline 11. & Chitosan- $\mathrm{Fe}_{3} \mathrm{O}_{4}$ & Acid orange 12 acid green 25 & $1.883,1.471$ \\
\hline 12. & $\mathrm{Fe}_{3} \mathrm{O}_{4} @ \mathrm{SiO}_{2} / \mathrm{SiCRG}$ & Metoprolol (MTP) & 447 \\
\hline
\end{tabular}

\subsection{Silsesquioxane Based Materials}

A silsesquioxane is an organosilicon compound with the chemical method [RSiO3/2 ] In $(\mathrm{R}=\mathrm{H}$, alkyl, aryl or alkoxyl) [33]. Silsesquioxanes are participants of polytetrahedral silsesquioxanes ("POSS"), that have attracted interest as precursors to ceramic substances and nanocomposites. The ability applications of silsesquioxane based materials lie inside the fields of catalysis [34-35], separation and garage [36-37], opto-electronics [38] and 
ICACCG2020 30-31 July, 2020, Ansal University, Gurgaon, India

International Journal of Technical Research \& Science (Special Issue) ISSN No.:2454-2024 (online)

environmental field [39]. Those substances are considerably used for the synthesis of nano dependent hybrid polymer substances, having nanometre sized inorganic cores surrounded with natural useful groups [33]

\section{CONCLUSION AND FUTURE PERSPECTIVES}

Inside the all evaluate article; numerous nanomaterials are reviewed which have been used for water decontamination. The unique emphasis inside the review has been given on adsorption, and antimicrobial properties of nanomaterials. As evident from the reviewed literature, a huge variety of nanomaterials have been tested for the removal of inorganic and/or organic pollution.

Many nanomaterials eventually gift a mighty alternative to traditional treatment methods because of increased adsorption and/or photocatalytic pastime and substance specificity. But most applications aren't yet geared up for the market because of technical challenges (e.g., scale up, device installation), environmental worries and feeeffectiveness and subsequently, only a few nanosized commercial merchandise are to be had in the market. Moreover, there are some different drawbacks related to nanomaterials use that need to be negotiated. Once in a while, the mass production of nanomaterials, for their practical use, is probably a hard issue. Moreover, the provision of substantial portions of nanomaterials at economically possible prices for water remedy functions may be a critical bottleneck for industrial programs. Advantages and limitations in the applications of nanomaterials are to remove heavy toxic metals, inorganic and organic pollutants from pollutant water very efficiently with high cost and also potential health risk and secondary pollution. Due to this, nanomaterials with lows cost and no potential health risk /eco risk is required.The instead excessive cost of carbon-based totally graphene substances and carbon nanotubes limits their commercial uses, and as an opportunity adsorbent for activated carbon, the conversion of agricultural waste to carbon-primarily based NMs for wastewater remediation is turning into a promising method.

Despite the fact that, nanomaterials could offer superb potential in water remedy and environmental remediation in the coming decades, specially designing of point-of-use systems, and within the entire degradation of emerging organic contaminants from water and wastewater.

Agricultural waste-based totally NMs including natural polymer cellulose-/chitosan-primarily based nano-sorbents provide leapfrogging opportunities for water remedy in place of luxurious artificial NMs and decrease the ability dangers. Meanwhile, the magic method of talking waste to fee meets the necessities of environmental friendly sustainability without sacrificing the performance. Finally, but, the toxicity and eco-compatibility of NMs still requires further take a look at.

\section{REFERENCES}

[1] Nemerow A.D.N., Industrial and Hazardous Waste Treatment, Van Nostrand Reinhold, New York, 1991.

[2] Ali H.Y.A.-E.I., Chiral Pollutants: Distribution, Toxicity and Analysis by Chromatography and Capillary Electrophoresis, John Wiley \& Sons, Chichester, UK, 2004.

[3] Helmer I.H.R., Water Pollution Control - A Guide to the Use of Water Quality Management Principles, E \& FN Spon, London, Great Britain, 199

[4] Nemerrow, N.L. Industrial Water Pollution: Origins, Characteristics, and Treatment, Addison-Wesley Publishing Company, Massachusetts, 1978.

[5] Forgacs, E., Cserháti,T., Oros,G., Removal of synthetic dyes from wastewaters: a review, Environ. Int. 30 (2004) 953-971.

[6] Rai, H.S., Bhattacharyya, M.S., Singh,J., Bansal, T.K., Vats, P., Banerjee, U.C., Removal of dyes from the effluent of textile and dyestuff manufacturing industry: a review of emerging techniques with reference to biological treatment, Crit. Rev. Environ. Sci. Technol. 35 (2005) 219-238

[7] Ali, I., Khan, A., Asim, M., Removal of arsenic from water by electrocoagulation and electrodialysis techniques, Sep. Purif. Rev. 40 (2011) 25-42.

[8] Gupta, V.K., Agarwal, S., Saleh, T.A., Synthesis and characterization of alumina coated carbon nanotubes and their application for lead removal, J. Hazard. Mater. 185 (2011) 17-23.

[9] Sanady, I.S.M.C., Health damage due to pollution in Hungary, in: Proceedings of the Rome Symposium, International Association of Hydrological Sciences, Wallingford, Oxfordshire, UK, 1995.

[10] Matschullat, J., Arsenic in the geosphere - a review, Sci. Total Environ. 249 (2000) 297-312.

[11] Gautam, R.K., Chattopadhyaya M.C., Nanomaterials for Wastewater Remediation, 1st Edi., ButterworthHeinemann, 2016

[12] Pacheco, S., Medina, M., Valencia, F, Tapia, J., Removal of inorganic mercury from polluted water using structured nanoparticles, J. Environ. Eng. 132 (2006) 342-349.

[13] Yang, K., Xing, B., Desorption of polycyclic aromatic hydrocarbons from carbon nanomaterials in water, Environ. Pollut. 145 (2007) 529-537.

[14] Hristovski, K., Baumgardner, A., Westerhoff, P., Selecting metal oxide nanomaterials for arsenic removal in fixed bed columns: from nano powders to aggregated nanoparticle media, J. Hazard. Mater. 147 (2007) 265274

[15] Khaleel, A., Kapoor, P.N., Klabunde, K.J., Nanocrystalline metal oxides as new adsorbents for air purification, Nano struct. Mater. 11 (1999) 459-468

[16] X.-Q. Li, Elliott, D. W., Zhang, W. X., Zero-valent iron nanoparticles for abatement of environmental pollutants: materials and engineering aspects, Crit. Rev. Solid State Mater. Sci. 31 (2006) 111-122. [36]

DOI Number: https://doi.org/10.30780/specialissue-ICACCG2020/030

Paper Id: IJTRS-ICACCG2020-030

pg. 40

@ 2017, IJTRS All Right Reserved, www.ijtrs.com 
ICACCG2020 30-31 July, 2020, Ansal University, Gurgaon, India

International Journal of Technical Research \& Science (Special Issue) ISSN No.:2454-2024 (online)

[17] Zhang, W.-X., Nanoscale iron particles for environmental remediation: an overview, J. Nanopart. Res. 5 (2003) 323-332.

[18] Jusoh, A., Shiung, L. Su., Ali,n.a., Noor, M.J.M.M., Euro Med 2006A simulation study of the removal efficiency of granular activated carbon on cadmium and lead, Desalination 206 (2007) 9-16.

[19] Wang, S., Peng, Y., Natural zeolites as effective adsorbents in water and wastewater treatment, Chem. Eng. J. 156 (2010) 11-24

[20] Kim, Y., Yi, J., Advances in environmental technologies via the application of mesoporous materials, J. Ind. Eng. Chem. 10 (2004) 41-51.

[21] Ren, X., Chen, C., Nagatsu, M., Wang, X., Carbon nanotubes as adsorbents in environmental pollution management: a review, Chem. Eng. J. 170 (2011) 395-410

[22] Rao, G.P., Lu, C., Su, F., Sorption of divalent metal ions from aqueous solution by carbon nanotubes: a review, Sep. Purif. Technol. 58 (2007) 224-231.

[23] Yang,K., Zhu, L., Xing, B., Adsorption of polycyclic aromatic hydrocarbons by carbon nanomaterials, Environ. Sci. Technol. 40 (2006) 1855-1861

[24] Sitko, R., Zawisza, B., Malicka ,E., Graphene as a new sorbent in analytical chemistry, TrAC, Trends Anal. Chem. 51 (2013) 33-43

[25] ZhaoJ, Z., Wang, J., White, C., Xing, B., Graphene in the aquatic environment: adsorption, dispersion, toxicity and transformation, Environ. Sci. Technol. 48 (2014) 9995-10009

[26] Zhao, G., Li, J., Ren, X., Chen, C., Wang, X., Few-layered graphene oxide nanosheets as superior sorbents for heavy metal ion pollution management, Environ. Sci. Technol. 45 (2011) 10454-10462

[27] Van Benschoten, J.E., Reed, B.E., Matsumoto, M.R., McGarvey, P.J., Metal removal by soil washing for an iron oxide coated sandy soil, Water Environ. Res. 66 (1994) 168-174

[28] Agrawal, A., Sahu, K.K., Kinetic and isotherm studies of cadmium adsorption on manganese nodule residue, J. Hazard. Mater. 137 (2006) 915-924.

[29] Henglein , A., Small-particle research: physicochemical properties of extremely small colloidal metal and semiconductor particles, Chem. Rev. 89 (1989) 1861-1873.

[30] El-Sayed, M.A., Some interesting properties of metals confined in time and nanometer space of different shapes, Acc. Chem. Res. 34 (2001) 257-264.

[31] Deliyanni, E.A., Peleka, E.N., Matis, K.A., Modelling the sorption of metal ions from aqueous solution by iron-based adsorbents, J. Hazard. Mater. 172 (2009) 550-558.

[32] Pan, B., Zhang, W., Lv, L., Zhang, Q., Zheng, S., Development of polymeric and polymer-based hybrid adsorbents for pollutants removal from waters, Chem. Eng. J. 151 (2009) 19-29

[33] Cordes, D.B., P.D. Lickiss, P. D. Rataboul, F., Recent developments in the chemistry of cubic polyhedral oligosilsesquioxanes, Chem. Rev. 110 (2010) 2081-2173.

[34] Seo, J.S., Whang, D., Lee,H.,Im Jun, S., Oh, J., Jeon,Y.J.,Kim, K., A homochiral metal-organic porous material for enantioselective separation and catalysis, Nature 404 (2000) 982-986.

[35] Christensen, C.H., Johannsen, K., Schmidt, I., Christensen, C.H., Catalytic benzene alkylation over mesoporous zeolite single crystals: improving activity and selectivity with a new family of porous materials, J. Am. Chem. Soc. 125 (2003) 13370-13371.

[36] White, R.J., Budarin, V., Luque, R., Clark, J.H., Macquarrie, D.J., Tuneable porous carbonaceous materials from renewable resources, Chem. Soc. Rev. 38 (2009) 3401-3418.

[37] Ding, S.-Y., Wang, W., Covalent organic frameworks (COFs): from design to applications, Chem. Soc. Rev. 42 (2013) 548-568.

[38] Patra, A., Scherf, U., Fluorescent microporous organic polymers: potential testbed for optical applications, Chem. A Eur. J. 18 (2012) 10074-10080.

[39] Hartmann, M., Kullmann, S.,Keller, H., Wastewater treatment with heterogeneous Fenton-type catalysts based on porous materials, J. Mater. Chem. 20 (2010) 9002-9017. [232] Q. Liu, L. Wang, A. Xiao, J. Gao, W. Ding, H. Y

[40] Liu, H. Puchberger, M., Schubert, U., A facile route to difunctionalized monosubstituted octasilsesquioxanes, Chem. A Eur. J. 17 (2011) 5019-5023.

[41] Liu,Y., Yang,W., Liu,H., Azobenzene-functionalized cage silsesquioxanes as inorganic-organic hybrid, photoresponsive, nanoscale, building blocks, Chem. A Eur. J. 21 (2015) 4731-4738

[42] Dinh, N.X., Lan, N.T., Lan, H., Van Tuan, H., Van Quy, N., Phan, V.N., Huy, T/Q. Le, A-T., Waterdispersible silver nanoparticles-decorated carbon nanomaterials: synthesis and enhanced antibacterial activity, Appl. Phys. A 119 (2015) 85-95.

[43] Ghasemzadeh, G., Momenpour, M., Omidi, F., Hosseini, M. R., Ahani, M., Barzegari, A., Applications of nanomaterials in water treatment and environmental remediation, Front. Environ. Sci. Eng. 8 (2014) 471-482.

[44] I. Gehrke, A. Geiser, A. Somborn-Schulz, Innovations in nanotechnology for water treatment, Nanotechnol. Sci. Appl.8(2015).1-17. 